\title{
An empirical analysis of cellular demand in South Africa ${ }^{1}$
}

\author{
Farid Gasmi \\ Toulouse School of Economics (ARQADE, GREMAQ, IDEI) \\ Marc Ivaldi \\ Toulouse School of Economics (EHESS, GREMAQ, IDEI) \\ Laura Recuero Virto \\ Télécom ParisTech (ENST/SES)
}

\begin{abstract}
We analyze demand for prepaid cellular voice and short message service (SMS) in South Africa by means of a demand-and-supply structural model based on a multinomial specification fitted to a cross-sectional data set on Vodacom customers collected in 2005. We find that consumers are very sensitive to changes in prices, with higher price elasticities than those typically found in developed countries. Consumers attach a higher value to communications during peak hours but since these are priced highly, they are as much as twice more elastic than off-peak communications. In relative terms, demand for communications during peak hours is more elastic for urban than for rural consumers, while the reverse can be said about demand for off-peak hours. The highest valuations are those placed by rural consumers on working hour communications. A policy implication of our analysis is that while in terms of access cellular deployment in South Africa has gone a long way into bridging the gap between the "first" and "second" economies, in terms of usage if market organizations or regulatory institutions were to encourage further investment in network availability in rural areas this could be rewarding both for the firm and its rural customers.
\end{abstract}

JEL-codes: C31, D12, D40, L96, R00

Key words: Cellular demand, discrete choice model, price elasticity

July 2008

\footnotetext{
${ }^{1}$ Corresponding author: recuerovirto@hotmail.com. An earlier version of this paper has been presented at the ENST and the PSE seminars, Paris, 2008, and at the ITS conference, Montréal, 2008, the EEA conference, Milan 2008, the EARIE conference, Toulouse, 2008, the AFSE conference, Paris 2008, the ITS conference, Rome 2008, and at the ASSET conference, Florence 2008. We thank participants to these events and Alison Gillwald for useful comments. We thank Vodafone for having provided us with the data on which this research is based. The views expressed in this paper and any remaining errors are only ours however.
} 


\section{Introduction}

Since 1994, the year of the advent of democracy in South Africa, this country has embarked in the ambitious task of reversing the apartheid socio-economic structure. ${ }^{2}$ However, the significantly high unemployment and poverty rates highlight the fact that South Africa is still divided upon racial lines. South Africa is indeed characterized by having a dual economy that is geographically segregated, with a so-called "first" economy, modern, integrated in the global economy, containing a (white) minority, and producing most of the economy's wealth, and a so-called "second" economy, underdeveloped, isolated from the global and first economies, containing most of the (black) population, and contributing only weakly to the economy's wealth (Van der Merwe, 2006). ${ }^{3}$

With the explicit recognition of the South African government that without addressing inequalities growth is not sustainable, the State has emphasized the need to mobilize capital for the implementation of a comprehensive set of reforms aimed at integrating the second economy within the developed sector under the Accelerated and Shared Growth Initiative for South Africa (AsgiSA) program. The development of infrastructures, in particular, telecommunications networks, occupies an important place in these reforms. The adoption of effective competition and effective regulation are taken as the guiding principles for achieving the national telecommunications policy objectives which are among other things, accessibility to telephony within a walking distance of no more than 500 meters, availability of fixed-line or cellular services in every household by 2010, and accessibility to Internet to no less than $25 \%$ of the population also by 2010 .

\footnotetext{
${ }^{2}$ Like many developing countries, South Africa has been strongly conditioned by its past colonial ruling. This ruling has however, engendered an apartheid regime that has marginalized the majority of the population through discriminatory legislation and practices that were present in every aspect of life. With the advent of democracy in 1994, South Africa has faced the formidable challenge not only of dismantling the apartheid political regime and creating democratic institutions, but also of addressing a soaring economic crisis and reversing the apartheid social and economic structures. By 2005, South Africa has succeeded in among other things, adopting a progressive constitution with democratic laws, achieving a macro-economic stability with a five percent growth, and keeping a budget deficit of less than one percent.

${ }^{3}$ It should be noted however that the first economy is increasingly being composed by a mixed population.
} 
In order to attain such network deployment objectives, both fixed-line and cellular telecommunications technologies have been relied upon. The fixed-line incumbent Telkom, has been recently privatized (1997) under a five-year exclusivity period in voice services with rather challenging built-out obligations that have unfortunately, resulted in high customer churn in rural areas (up to 70\%) due to unaffordable bills. The cellular segment has been liberalized with the introduction, next to the existing analogue operator Vodacom, of three other digital competitors, Vodacom (with $50 \%$ of its capital owned by Telkom), MTN, and CellC operators. ${ }^{4}$ These digital cellular operators have been also imposed a series of built-out obligations which are being accomplished quite successfully. More than $90 \%$ of the population is currently covered directly by these operators or indirectly through interconnection agreements with Vodacom.

Cellular service appears to be better adapted than fixed-line service to customer requirements is terms of pricing and mobility as shown by the growth rates during 2004-2005. Indeed, this period has known an exponential growth of $38.2 \%$ in cellular subscribers to be compared with a weak $1.8 \%$ growth in fixed-line deployment. The figures on coverage are quite instructive too as 76.8 per 100 inhabitants have subscribed to cellular while only 10.7 per 100 inhabitants have subscribed to fixed-line service by 2005. This dynamic cellular market is unequally shared by the operators with Vodacom possessing over $50 \%$ of the market, MTN around $30 \%$, and CellC around 15\%. In terms of revenues, the cellular market is expected to grow up to 54 billion Rands by 2007 .

As encouraging these figures may seem, the cellular market practices have been closely monitored by ICASA, the telecommunications regulator created in 2000 under the Department of Communications. Indeed, such high cellular growth rates have been accompanied by a series of decisions that could potentially hinder consumer welfare. Among other things, the 2005 report of The Telecommunications Pricing Working Group has pointed out the banding of two-year contracts to handset sales, the high prices for voice and SMS

\footnotetext{
${ }^{4}$ The analogue operator Vodacom, operates in C-Netz 450 since 1986. As for the digital operators, Vodacom operates on GSM 900, GPRS, and MMS since 1994, and on 3G 2,100 since 2004; MTN on GSM 900 since 1994, GSM 1,800 since 2003, and 3G 2,100 since 2005; CellC on GSM 900, and GSM 1,800 since 2001.
} 
communications, the penalization of prepaid subscribers in terms of pricing as compared to contract subscribers, and the $500 \%$ increase in the cellular operators interconnection tariffs. ${ }^{5}$

While the cellular subscription figures render unquestionable the fact that in terms of access, the cellular market has been so far able to bridge the telecommunications gap between the first and second economies, the situation is not so clear in terms of usage as the conclusions of the ICASA report suggest. This situation which can be extrapolated to other developing countries experiences, lead us to explore how market organizations and regulatory institutions can adapt to the specificities of demand in such a context in order to maximize both firms' profits and consumer welfare.

In this sense, the major contribution of this article resides on the fact that despite the important changes experienced recently by the telecommunications market in Sub-Saharan Africa, there are, to our knowledge, no micro-econometric studies that analyze data stemming directly from operators. Indeed, the bulk of the empirical literature in telecommunications is constituted of macroeconomic studies based on aggregated country information or microeconomic studies based on consumers surveys. Our paper is a micro-econometric study based on revealed preferences data on South Africa provided by the operator Vodacom. Hence, it departs from most of the other micro-econometric studies in the field that are based on stated preferences data, i.e., on data generated through surveys.

Relying then on a Vodacom cross-sectional data set on 6,936 consumers collected in May 2005 in South Africa, we attempt to shed some light on cellular phone demand in terms of usage. We focus on the prepaid market that makes the bulk of Vodacom's cellular growth with over $85 \%$ of the new subscriptions in 2005 having adopted this type of service. Moreover, this service accounts for $75 \%$ of the communications in the Vodacom data set. ${ }^{6}$ We explore both voice and SMS communications as $58.9 \%$ of the growth in data revenue in Vodacom's network in 2005 is imputable to the 2 billion SMS transmitted.

\footnotetext{
${ }^{5}$ Network operators do not necessarily agree with ICASA's statements. In particular, their views do not coincide with respect to the amount of increase in interconnection tariffs.

${ }^{6}$ Notice however that contract subscribers contribute equally if not more to the volume and revenue of Vodacom.
} 
In this article, we analyze own-price and cross-price elasticities between different services offered by Vodacom for prepaid voice and SMS among which we are accounting for peak and off-peak hours and for the type of correspondent, that is, a Vodacom, MTN, CellC, or Telkom subscriber. We therefore explore prepaid retail prices and also implicitly interconnection prices. We develop a demand-and-supply structural model based on the multinomial specification which we apply to the whole sample. This allows us evaluate whether demand for cellular services is elastic as a consequence of high tariffs and low average income, with higher price elasticities than those typically associated with developed countries.

We then apply this model to two sub-samples that identify urban and rural Vodacom consumers, which allows us to empirically analyze the behavior of consumers from the first and second economies. We attempt to test the conjecture that price elasticities are lower for rural consumers since among other things, major labor opportunities are concentrated in cities. Indeed, rural consumers should have a stronger preference for cellular services as it allows them to bypass more costly means of communications such as public transportation. Lastly, we give some insights on the role of market organizations and regulatory institutions under such environment.

This article is organized as follows. In section two, we give an overview of the empirical literature on price elasticities associated with telecommunications services in developing countries. In section three, we provide a preliminary empirical analysis of the data set that allows us to define our econometric setting by exploring some socio-economic features and by analyzing consumer choice. In section four, we develop the structural model under a demand-and-supply analysis, present the calibration procedure to solve the system and report the associated results. In section five, we summarize our findings and discuss some policy implications.

\section{Price elasticities for telecommunications ser- vices in developing countries}

While the literature analyzing telecommunications demand in developed countries is fairly large, there are very few studies on this topic with data sets 
on developing countries. ${ }^{7}$ The major motivation for exploring price elasticities in developing countries, comes from the belief that these figures might not coincide with those typically found in developed countries. Once an initial penetration level has been attained in developing countries, the network serves not only wealthy residential and business consumers, but also the bulk of the low-income population. Among the most relevant differences, developing countries' networks are usually characterized by having telephone bills that represent a much higher percentage of average income, by having a lower percentage of business communications and by having a certain degree of unmet demand.

Driven by these reasons, two main streams of empirical literature have risen in the recent years on telecommunications demand in developing countries. There is a stream of literature on cross-country analysis based on macroeconomic indicators that provides some evidence of directions of change and orders of magnitude. There is a very thin but more reliable stream of literature on single-country analysis based on household surveys measuring stated preferences. In this article we attempt to provide further evidence on price elasticities in line with this last stream of literature but based on revealed rather than on stated preferences, since we are relying on network information.

Within the cross-country studies, Fuss et al. (2005) focus on the usage of telecommunications services. They analyze demand for cellular subscription on a data set on 92 developing countries for the period 1980-2003, finding a price elasticity of -1.5 . This result is nevertheless difficult to interpret since price is captured through revenue per subscriber. There are other crosscountry investigations that draw their attention not only towards usage but also towards access to telecommunications services. ${ }^{8}$ Some of these studies use a price index that accounts both for rental subscription and for the price of average minutes of usage. Using a data set on 74 countries for the years 1980 and 1985, Martins (2003) provides evidence of differences

\footnotetext{
${ }^{7}$ See Aldebert et al. (2004) for a short summary on the evolution of telecommunications demand in developed countries.

${ }^{8}$ Indeed, while access is no more the focus in developed countries due to the large network expansion, this does not hold for every developing country. For example, OSIPTEL, the telecommunications regulator in Peru finds that "..one of the barriers for new mobile users is the handset cost."
} 
in price elasticities for fixed-line services according to the country level of development. Elasticities are over the unity and are systematically larger in the sample of low-income countries as compared to the sample of highincome countries whatever the specification used. Wheatley (2006) explores demand for fixed-line services with a data set on 40 low-income countries in 1993. Though the elasticity he finds is below the unity, it is still above that typically reported in developed countries. ${ }^{9}$

Some authors instead examine disaggregated measures of price elasticity according to usage and access. By using a data set on 63 developing countries for the period 1990-2001, Sridhar and Sridhar (2004) find that demand both for fixed-line and cellular subscription is more sensitive to changes in access price as measured through the rental tariffs than to changes in usage price as captured by revenue per user. In addition, they observe that demand for cellular subscription is more elastic than for fixed-line whatever price index used. ${ }^{10}$ Like in Fuss et al. (2005), some of their results are however difficult to interpret with usage being captured by revenue per user. In the GSM Association (2005) report, demand for cellular subscription is analyzed with a four year data set on 50 emerging countries. In the report prepaid demand is more elastic than demand under contracts, with a price elasticity of -0.7 as compared to -0.5, where price accounts for subscription and minutes of usage. Moreover, they find that the elasticity is the highest for demand for handsets with a value of $-1.0 .^{11}$

Some single-country analysis based on surveys provide more reliable insights on price elasticities in developing countries than the previous crosscountry analysis. Chowdhury et al. (2003) measure rural consumers' willingness to pay in Bangladesh and Peru for public fixed-line and cellular services

\footnotetext{
${ }^{9}$ Wheatley (2006) finds a price elasticity of -0.6 for rental and local calls, while the typically reported in developed countries is between -0.1 and -0.6 for rental and between -0.1 and -0.5 for local calls.

${ }^{10}$ Overall in the literature there is evidence that in developed countries demand for cellular service is more elastic than demand for fixed-line services (Dewenter and Haucap, 2004).

${ }^{11}$ Price elasticities of cellular demand are in general smaller in developed countries than in developing countries. Indeed, the UK Competition Commission has reported own-price elasticities of mobile subscriptions between -0.08 and -0.54 . For mobile calls, own-price elasticities between -0.48 and -0.62 have been measured. See Dewenter and Haucap (2004) for a summary of typical price elasticities of cellular demand in developed countries.
} 
using a cross-sectional data set on 1,284 households. Their results suggest that households' willingness to pay for a single call is higher than the prevailing tariff rates. ${ }^{12}$ However, this study included settlements without a public telephone and therefore the value of the first call for these users could be quite high.

Certain regulatory institutions have also studied telecommunications demand in developing countries through household surveys. Using a crosssectional data set on 1,759 households, the CRT (2005) report explores demand in terms of usage for fixed-line and cellular services in Colombia. They find that demand for long distance calls is more elastic than demand for local calls, with an elasticity of -0.9 as compared to the range of $\{-0.4,-0.9\}$. Demand for cellular services, with elasticities over the unity, is more elastic than demand of fixed-line services. OSIPTEL (2005) with a cross-sectional data set on 1,604 households finds that in terms of access the price elasticity for fixed-line services for low-income consumers in Peru is over the unity, specially at high rates. In line with these analyses, in this article we attempt to provide further evidence on price elasticities by using a Vodacom cross-sectional data set for the year 2005 with 6,936 individuals in South Africa. We focus on price elasticities associated with the usage of voice and SMS services which currently seems a more crucial issue than access in South Africa. ${ }^{13}$ We compare urban and rural consumption patterns under the expectation that the demand for cellular services is more elastic for urban than for rural consumers mainly due to the cost of alternatives borne by rural users.

\section{Preliminary empirical analysis}

In this section we examine some of the properties of the data set that help us in defining our econometric framework. We begin by describing the main

\footnotetext{
${ }^{12}$ The Grameen Technology Center (2005) report illustrates a similar scenario. They describe how poor rural users in Uganda were ready to pay for a one minute call up to $20 \%$ of their daily gross earnings for a day.

${ }^{13}$ Notice however that given the disparity of income levels, it would be important to assess the impact of any pricing strategies or policies considered on the affordability of access to services. For example, a decrease in usage prices could lead to an increase in access prices, which would be to the determent of the so-called second economy.
} 
ingredients of this data set. We then identify some of the socio-economic characteristics associated with the areas of South Africa under study, and discuss the correlations between these features and the exerted voice or SMS communication. ${ }^{14}$ These analyses allow us to evaluate whether there is sample selection and explore the characteristics of urban and rural sub-samples, and of voice and SMS communications. We lastly focus on consumer choice by analyzing both the pricing scheme applied to each of the options Vodacom users are facing and the consumer behavior derived from some basic statistics in our sample. These enable us to select the appropriate consumer choice set for our econometric modeling and to further investigate whether there are behavioral differences between urban and rural sub-samples and between voice and SMS communications.

Our data set consists on network information collected by Vodacom on 6,936 individuals in South Africa on May 2005. ${ }^{15}$ The data accounts for voice and SMS communications originated by prepaid Vodacom consumers identifying the day and the time of the communication, as well as the location of user placing the communication, according to a urban vs rural classification. In addition, we are able to retrieve the type of prepaid card used by the Vodacom consumer. The data also captures the correspondent's network which can be the cellular operator Vodacom, the fixed-line incumbent Telkom, or the other cellular operators CellC and MTN.

Regarding the areas of South Africa under study, in Table 1 hereafter we can see the province, town and suburb where the communications were originated as well as for each area, the urban vs rural nature, the number of samples in our data set and the average income. ${ }^{16}$ Our data set contains,

\footnotetext{
${ }^{14}$ Statistics South Africa is the source of our socio-economic variables. In particular, 2000 statistics for income ("Income and expenditure of households"), and 2001 Census for the other variables ("Census 2001: Primary tables"). The socio-economic data is not individual specific, but rather derived from the province where the communication was originated and from the urban vs rural nature of the area. Therefore, this analysis should be seen as a preliminary study to have a better understanding of the nature of our data set and not an exhaustive and precise exploration.

${ }^{15}$ Information was collected for six time frames in May: Monday 2nd between 10h-11h, Friday 6th between 10h-11h, Saturday 14th between 20h-21h, Wednesday 18th 20h-21h, Sunday 22nd between 10h-11h and Tuesday 24th between 10h-11h.

${ }^{16}$ The income is assigned depending on the province, the urban vs rural nature of the area and, in some cases, the town. Since this data is extracted from 2000 statistics, 2005 income has been adjusted with the gross domestic product deflator.
} 
among other regions, the less developed areas of South Africa. ${ }^{17}$ Moreover, a casual look at Table 1 brings our attention to the fact that of 6,936 samples in our data set, $70.6 \%$ belong to rural areas which are those in the most eastern part of South Africa. Income is significantly lower in rural areas as compared to urban areas, as much as three times. In addition, while income does not vary too much between the three surveyed rural areas, it does vary significantly when comparing the surveyed urban areas, with Pretoria and Queenstown lagging behind.

Table 1

Average income in surveyed areas

\begin{tabular}{llllrr}
\hline \hline Province & Town & Suburb & Zone & Obs. & Income \\
\hline Mpumalanga & Pilgrim Rest & Open Space & Rural & 685 & 24,668 \\
Kwazulu Natal & Nqutu & Open Space & Rural & 1,617 & 17,473 \\
Limpopo & Thohoyandou & Open Space & Rural & 2,598 & 21,282 \\
Limpopo & Polokwana & New Pietersburg & Urban & 822 & 65,945 \\
Gauteng & Pretoria & Pretoria Ctl & Urban & 41 & 47,781 \\
Gauteng & Vereeniging & Vereeniging Ctl & Urban & 390 & 65,945 \\
North West & Mafikeng & Montshiwa & Urban & 470 & 67,446 \\
Eastern Cape & Queenstown & Top Town & Urban & 313 & 40,845 \\
\hline
\end{tabular}

In Table 2, we can see a series of statistics associated with each of the six provinces under study. Population is the population in the province as $\%$ of the country population, Young is the $\%$ of population under the age of 20 in the province, No education is the $\%$ of population aged 20 years or older without schooling in the province, Labor is the $\%$ of population aged between 15-65 employed in the province, Water is the \% of population whose main water supply is piped water in the province, and Light is the \% of population whose energy source is electricity in the province. ${ }^{18}$ In this table, Gauteng and North West which are located in the north-center of the South Africa, are those provinces with the best indices in terms of education, labor force, and

\footnotetext{
${ }^{17}$ Six of the nine provinces in South Africa are represented in our data set. They are in the half east of the country, where African is the dominant population group, and where there is no common dominant language group across provinces. Relative to the two provinces in the west of the country, Northern Cape, and Western Cape, the provinces in our data set have higher density levels, lower population age, larger population with no schooling and fewer economically active population.

${ }^{18}$ The Census 2001 considers that piped water can be taken as main supply of water when it is inside the dwelling, inside the yard, or on a community stand located at approximately $200 \mathrm{~m}$.
} 
infrastructure, and with the lowest percentage of young inhabitants. Eastern Cape is certainly lagging behind in terms of infrastructure, and Limpopo in terms of education having the latter in addition the highest percentage of young inhabitants. Accordingly, there does not appear to be any severe problem of sample selection between the urban and rural sub-samples. ${ }^{19}$

Table 2

Socio-economic characteristics by province (\%)

\begin{tabular}{lcccccc}
\hline \hline Province & Population & Young & No education & Labor & Water & Light \\
\hline Mpumalanga & 6.9 & 47.0 & 27.5 & 23.0 & 86.7 & 68.3 \\
Kwazulu Natal & 20.6 & 46.7 & 21.9 & 27.8 & 73.2 & 61.8 \\
Limpopo & 12.0 & 52.6 & 33.4 & 22.0 & 78.0 & 63.8 \\
Gauteng & 19.2 & 32.1 & 8.4 & 45.0 & 97.5 & 80.8 \\
North West & 8.2 & 41.9 & 19.9 & 31.8 & 85.8 & 70.5 \\
Eastern Cape & 15.0 & 49.4 & 22.8 & 20.4 & 62.4 & 49.5 \\
\hline
\end{tabular}

An examination of Table 3 points out the differences in the correlations between the previous socio-economic characteristics and the type of voice or SMS communication exerted. Indeed, when the sample is analyzed by the type of communication we can see that SMS are positively correlated with the level of development in the area, that is, the more SMS sent, the lower levels of young inhabitants, higher levels of education and employment, better infrastructure and higher income. Voice takes on the counterpart of SMS correlations, being positively correlated with Young and No education, and negatively correlated with Labor, Water, Light, and Income.

Table 3

Correlations between

the socio-economic features and the type of communication

\begin{tabular}{lccccccc}
\hline \hline & Population & Young & No education & Labor & Water & Light & Income \\
\hline Voice & -0.090 & 0.318 & 0.315 & -0.290 & -0.137 & -0.137 & -0.221 \\
SMS & 0.090 & -0.318 & -0.315 & 0.290 & 0.137 & 0.137 & 0.221 \\
\hline
\end{tabular}

If we further examine voice communications by analyzing the correlation between the socio-economic characteristics and the duration of the voice call

\footnotetext{
${ }^{19}$ Indeed, urban surveyed provinces include the most and least developed areas, i.e., Gauteng and North West, and Eastern Cape, respectively. Rural surveyed provinces include moderate areas in terms of development. Limpopo, in particular, is subject to both urban and rural analyses.
} 
in seconds for the total sample and for the sub-sample of rural areas, in Table 4 we can see some interesting features through some rough Ordinary Least Squares (OLS) estimations under the standard assumption of an homoskedastic error structure. ${ }^{20}$ Infrastructure is negatively correlated with the duration of the voice call, which could signal the dependence of isolated communities upon cellular devices. In addition, the older the population and the higher the income, the longer the duration of the call. Surprisingly, the correlation between the income and the duration of the voice call switches to negative in the rural sub-sample. This might indicate that poor users in rural areas might have greater need for cellular services due to the cost of alternatives.

Table 4

Correlations between

\begin{tabular}{lllll} 
the socio-economic features and the duration of the voice call \\
\hline \hline OLS & $\begin{array}{c}\text { Total } \\
\text { sample }\end{array}$ & $\begin{array}{c}\text { Rural } \\
\text { sub-sample }\end{array}$ & $\begin{array}{c}\text { Rural } \\
\text { sub-sample }\end{array}$ & $\begin{array}{c}\text { Rural } \\
\text { sub-sample }\end{array}$ \\
\hline Population & -0.338 & $0.493^{*}$ & & \\
Young & $-1.523^{* * *}$ & $-2.006^{* * *}$ & $-2.324^{* * *}$ & $-2.122^{* * *}$ \\
Water & $-1.133^{* * *}$ & & $-0.494^{*}$ & $-0.001^{*}$ \\
Income & $0.001^{* *}$ & & & \\
\hline
\end{tabular}

Focusing now on consumer choice we are first concerned with the pricing schemes faced by Vodacom consumers. Actual choices made by users depend on prices and these are charged according to the type of prepaid card, to whether the type of communication is voice or SMS, to whether the communication is made during peak or off-peak hours, and to the network of the correspondent. Regarding prepaid offers, there are three possibilities. $4 \mathrm{U}$ Prepaid (4UP) advantageous for off-peak hours, Vodago (VGO) advantageous for peak hours, and Vodago SmartStep (VSS) that treats peak and off-peak hours in equal terms. The prepaid cards are not evenly selected in our sample. From 6,259 prepaid voice communications, $93.3 \%$ are 4UP, 5.9\%

\footnotetext{
${ }^{20}$ In Table 4, in the case of the total sample, Young, No education and Labor, on the one hand, and Water and Light, on the other hand, have correlation coefficients over 0.9 and are thus not simultaneously included in the OLS estimation to avoid multicollinearity. In the case of the rural sub-sample, Water and Income, Water and Population, and Income and Population are additionally correlated over 0.9 , and similarly they are not included simultaneously in the estimations. In Table 4 and for the entire document $* * * / * * / *$ indicate significance at the $1 / 5 / 10 \%$ level.
} 
are VGO and $0.8 \%$ are VSS. As for SMS, from 677 prepaid messages, $83.2 \%$ are $4 \mathrm{UP}, 14.1 \%$ are VGO and $2.7 \%$ are VSS.

The user has to choose among placing a voice call or sending an SMS. In the first case, the service is billed per minute of communication, while in the second, the service is billed per message. The user also has to decide upon placing a communication during peak or off-peak hours, where peak hours are Monday to Friday from 7am to 10pm and off-peak hours are the remaining time frames. Finally, the user has to select the correspondent whose network can be mobile, that is, Vodacom, MTN or CellC, or fixed-line, that is, Telkom. Since users are charged identically by the Vodacom network when they communicate with Vodacom or Telkom, on the one hand, and with CellC or MTN, on the other hand, we work hereafter with two type of network correspondents instead of four. Tables 5 and 6 hereafter display the prices for each of these previous options.

Table 5

Voice prepaid prices per minute

\begin{tabular}{llccc}
\hline \hline Correspondent & Hour & \multicolumn{3}{c}{ Prepaid card } \\
& & 4UP & VG0 & VSS \\
\hline Vodacom-Telkom & Peak & 2.99 & 2.55 & \\
Vodacom-Telkom & Off-Peak & 1.05 & 1.40 & $2.701^{\text {st }}$ min \\
CellC-MTN & Peak & 2.99 & 2.85 & 1.55 after \\
CellC-MTN & Off-Peak & 1.30 & 1.65 & \\
\hline
\end{tabular}

Table 6

SMS prepaid prices per message

\begin{tabular}{llc}
\hline \hline Correspondent & Hour & Prepaid card \\
\hline All & Peak & 0.80 \\
All & Off-Peak & 0.35 \\
\hline
\end{tabular}

A close examination of some statistical features in our data set can provide further information on consumer choice by giving preliminary evidence on consumer preferences. We focus on the number of observations associated with the alternatives which are kept as relevant according to the previous 
analysis on pricing schemes, that is, voice/SMS communications, peak/offpeak hours, and Vodacom-Telkom/CellC-MTN correspondents. ${ }^{21}$ In Table 7, we see that there are about 10 times more voice calls than SMS. Moreover, the 1.5 to one ratio Vodacom-Telkom to CellC-MTN is similar for both voice and SMS communications, and peak and off-peak hours. In addition, whatever the type of correspondent, the sample size for consumers using voice communications is fairly similar in peak and off-peak hours while, when it comes to SMS, there are two to three times more messages during off-peak than during peak hours.

Table 7

Consumer choice: Total sample

\begin{tabular}{lc}
\hline \hline Combination of alternatives & Number of observations \\
\hline Voice/Vodacom-Telkom/Peak & 2,007 \\
Voice/Vodacom-Telkom/Off-Peak & 1,978 \\
Voice/CellC-MTN/Peak & 1,022 \\
Voice/CellC-MTN/Off-Peak & 1,252 \\
\hline SMS/Vodacom/Peak & 112 \\
SMS/Vodacom/Off-Peak & 296 \\
SMS/CellC-MTN/Peak & 78 \\
SMS/CellC-MTN/Off-Peak & 191 \\
\hline
\end{tabular}

If we now analyze the number of observations associated with the different alternatives according to the type of Vodacom consumer, that is, urban vs. rural, we obtain the figures exhibited in Table 8. It is striking that prepaid rural consumers make around five times more voice calls than urban consumers during peak hours whatever the correspondent type, even if in our sample there are only twice as many rural than urban consumers. Another striking feature is that despite the larger number of rural consumers surveyed, urban consumers send more SMS, as much as the double during off-peak hours. ${ }^{22}$ If we compare urban and rural sub-samples in Table 8 with the total sample in Table 7, we still find that overall consumers place about twice more voice/SMS communications towards Vodacom-Telkom as

\footnotetext{
${ }^{21}$ In Table 7 we can see that all alternatives have a size greater than 30 , minimum that is necessary to obtain reliable estimations (McFadden, 1984).

${ }^{22}$ This might reflect that urban consumers have better knowledge of how to use mobile phones due to a typically higher educational level.
} 
compared to CellC-MTN. However, while urban consumers place twice more voice calls and send three times more SMS during off-peak hours than during peak hours whatever the correspondent, rural consumers have a different consumption pattern. They send fewer SMS, twice more SMS during offpeak hours than during peak hours whatever the correspondent, and they make more voice calls during peak times than during off-peak hours.

We can draw four lessons from this preliminary analysis. First, we find evidence that supports the use of separate models for voice and SMS communications due to their different underlying socio-economic characteristics, pricing scheme, and sample pattern (see Tables 3, 6, 7 and 8). Second, the analysis uncovers consumer choice, that is, a consumer in possession of a certain type of prepaid card who wants to make a voice call or send an SMS has the following options: the time of the communication which are peak or off-peak hours, and the type of network correspondent which can be Vodacom-Telkom or CellC-MTN. ${ }^{23}$ An outside option exists to account for all other choices. ${ }^{24}$ Third, we find in the total sample that we are accounting for the African dominant population provinces that contain, among other regions, the less developed areas of South Africa. Forth and last, the exploration calls for a separate analysis of urban and rural consumers and also provides some evidence that one could use this division to proxy the first and second economies in South Africa. Indeed, the analysis reveals significant differences between the urban and rural sub-samples in terms of income levels, income impact on voice and SMS communications and behavior in terms of usage (see Tables 1, 4 and 8, respectively). Moreover, there is no severe problem of sample selection in these urban and rural sub-samples.

\footnotetext{
${ }^{23}$ Notice that even if the price per message does not differ according to the type of correspondent (see Table 6), the preliminary sample analysis suggests accounting for VodacomTelkom and CellC-MTN as separate SMS options due to the differences in the sample sizes of the alternatives.

${ }^{24}$ This outside option take accounts for cases where the the individual is not using the mobile phone or is making some other choices, e.g., placing an international call.
} 
Table 8

Consumer choice: Urban and rural sub-samples

\begin{tabular}{lcc}
\hline \hline Combination of alternatives & \multicolumn{2}{c}{ Number of observations } \\
& Urban consumer & Rural consumer \\
\hline Voice/Vodacom-Telkom/Peak & 334 & 1,673 \\
Voice/Vodacom-Telkom/Off-Peak & 692 & 1,286 \\
Voice/CellC-MTN/Peak & 158 & 864 \\
Voice/CellC-MTN/Off-Peak & 401 & 851 \\
\hline SMS/Vodacom/Peak & 63 & 49 \\
SMS/Vodacom/Off-Peak & 211 & 85 \\
SMS/CellC-MTN/Peak & 47 & 31 \\
SMS/CellC-MTN/Off-Peak & 130 & 61 \\
\hline
\end{tabular}

\section{Structural model}

In this section we estimate a demand-and-supply structural model for the Vodacom prepaid cellular market in South Africa, with separate models for voice and SMS communications. ${ }^{25}$ Hereafter, we describe first the demand model which follows the multinomial specification in Berry (1994) and second, the supply model for a multiproduct monopole. We then explain the calibration procedure used to solve the demand-and-supply system of equations. We finally report the results of the model and the price elasticities for the total sample, and for the urban and rural sub-samples.

\subsection{Demand}

We assume a random utility model based on the deterministic decision rules from the neoclassical economic theory, but where uncertainty is captured by random variables. In both the voice and SMS analyses and derived from the examination performed in section three, demand for the use of cellular services is captured through a discrete choice model. Data is aggregated according to the choice of the consumer in a set of J products,

\footnotetext{
${ }^{25}$ See section three for the arguments justifying the choice of analyzing separately voice and SMS communications. These have been anyway subject to several joint regressions under multinomial logit and nested logit structures in order to identify own-price and cross-price elasticities with no consistent results.
} 
$j=1, . ., J=4$, contingent on the hour of the communication and on the type of correspondent: Vodacom-Telkom/peak, Vodacom-Telkom/off-peak, CellC-MTN/peak, CellC-MTN/off-peak, and where $j=0$ accounts for an outside option. ${ }^{26}$ We are assuming that products are competing symmetrically under the multinomial logit specification. ${ }^{27}$ Figure 1 below shows the choice model.

\section{Figure 1}

\section{Choice set: Multinomial logit}

$\begin{array}{ccccc}\swarrow & \downarrow & \downarrow & \downarrow & \searrow \\ \begin{array}{c}\text { Vodacom-Telkom } \\ \text { peak }\end{array} & \begin{array}{c}\text { Vodacom-Telkom } \\ \text { off-peak }\end{array} & \begin{array}{c}\text { CellC-MTN } \\ \text { peak }\end{array} & \begin{array}{c}\text { CellC-MTN } \\ \text { off-peak }\end{array} & \begin{array}{c}\text { outside } \\ \text { option }\end{array}\end{array}$

We choose to follow the methodology derived by Berry (1994) which allows the use of instrumental variable techniques that are otherwise not applicable in the context of discrete choice models under aggregated data where endogenous regressors enter the demand equation non linearly. ${ }^{28}$ Both for voice and SMS communications, the utility of consumer $i$ for product $j$ depends on the characteristics of the consumer and the product

\footnotetext{
${ }^{26}$ The demand for usage of telecommunications services is often modeled using individual data. It is sometimes modeled through a continuous system of equations with each equation dealing with one traffic direction (local, long distance, international, towards mobile, ..) and depending on the prices of all other traffic directions (Wolak, 1996). Discrete choice models have also been used to model this type of demand, where consumers select a portfolio defined as a particular number and average duration of calls to each traffic direction and during each time of the day (Train et al., 1987). Unlike these investigations, we lack information on total communications associated with each consumer during a period, but deal with a punctual communication made by a consumer at a certain time. Hence, in order to be able to estimate interactions between consumer choices, we choose to aggregate data.

${ }^{27}$ This assumption might be seen as constraining as one could suspect, e.g., some product differentiation between placing a communications towards Vodacom-Telkom or towards CellC-MTN, from the pricing scheme and sample structure described in section three. However, no consistent results with random utility maximization were obtained under more complex specifications such as the nested logit that relax this so-called Independence from Irrelevant Alternatives (IIA) assumption.

${ }^{28}$ Notice that while there is no endogenity problem when dealing with individual data since individual consumers cannot alter prices there is however, this concern once the data is aggregated.
} 


$$
u_{i j}=\delta_{j}+\epsilon_{i j}
$$

where $i=1,2, \ldots, N, \quad j=1,2, \ldots, J, \quad \delta_{j}$ is the deterministic part or the mean valuation of product $j$ common to all consumers, $\epsilon_{i j}$ is a one-dimensional random variable reflecting the consumer's $i$ deviation from the mean valuation of product $j .^{29}$ There are $N$ potential consumers where each chooses one product $j$ that maximizes its' utility. This number of potential consumers, $\mathrm{N}$, is the observed number of voice or SMS communications multiplied by $1+\mathrm{r}$, where $\mathrm{r}$ is the potential market factor. ${ }^{30}$ The observed number of consumers is 6,257 for voice and 677 for SMS, and $J=4$ in both cases. Next, taking a closer look at the mean valuation of product $j$ we have

$$
\delta_{j}=\psi_{j}-\alpha p_{j}+\xi_{j}
$$

where $\psi_{j}$ is a scalar parameter representing the quality of product $j, p_{j}$ is a one-dimensional regressor representing the price of the product $j, \alpha$ is the sensitivity of utility to price or marginal utility of income, and $\xi_{j}$ is the mean of the consumers valuations of unobserved product characteristics. For this model to be consistent with random utility maximization, $\alpha$ has to be positive.

Given equation (2) and assuming that the random term, $\epsilon_{i j}$, is identically and independently distributed across products and consumers with an extreme value distribution, the probability that a potential consumer chooses product $j$ is given by

$$
s_{j}=\frac{e^{\delta_{j}}}{\sum_{k=0}^{J} e^{\delta_{k}}}
$$

where

\footnotetext{
${ }^{29}$ In other words, $\epsilon_{i j}$ represents consumer's $i$ unobserved product valuations, e.g., consumer's $i$ failure rate or voice quality when placing a communication towards the fixed-line operator Telkom during peak hours.

${ }^{30}$ Accounting for different values of the potential market factor allows us to perform a sensitivity analysis, task taken up in section 4.3. Notice that exploring only the actual market instead of the potential one may lead to undesired overestimates in aggregated price elasticities (Ivaldi and Verboven, 2005). Indeed, as the potential market increases, the difference between the mean utility level of the inside good and the outside good is lower, more consumers will switch to the outside alternative in case of an increase in the price of the inside good and thus, the cross-price elasticity between the inside and the outside good, $\alpha p_{\text {outside }} r /(1+r)$, increases.
} 


$$
s_{j}=q_{j} / N
$$

with $q_{j}$ being the observed quantity of the product $j$, i.e, the number of voice or SMS communications held by Vodacom consumers during the survey, and $s_{j}$ the observed market share of product $j$. Therefore, at an aggregate level the choice probability coincides with the market share. We can then invert this predicted market share, to obtain an analytic expression for the mean valuation of the product, $\delta_{j}$, as a function of the demand parameters:

$$
\ln \left(s_{j}\right)-\ln \left(s_{0}\right)=\delta_{j} \equiv \psi_{j}-\alpha p_{j}+\xi_{j}
$$

where $s_{0}$ is the market share of the outside good. We make the standard assumption that the outside option yields zero utility. Furthermore, the net consumer surplus, $C S$, which indicates the attractiveness of the set of $J$ products once the price payed by consumers has been substracted, has the following expression

$$
C S=\frac{1}{\alpha} \ln \left(1+\sum_{j=1}^{J} \exp ^{\delta_{j}}\right)
$$

In this model, price elasticities, namely, the own-price elasticity of demand for product $j, \eta_{j, j}$, and the cross-price elasticity between products $j$ and $k, \eta_{j, k}$, are given by

$$
\begin{gathered}
\eta_{j, j}=-\alpha p_{j}\left(1-s_{j}\right) \\
\eta_{j, k}=\alpha p_{k} s_{k}
\end{gathered}
$$

As we already mentioned, in this setting with aggregated data estimation can be potentially plagued by endogeneity. One can reasonably expect prices to be correlated with unobserved product characteristics $\left(\xi_{j}\right)$. This suggests the use of instruments and therefore, we develop hereafter the supply model in subsection 4.2 .

\subsection{Supply}

The Vodacom firm produces two sets of products, voice and SMS communications. Each set is composed of $j=1,2, \ldots, J=4$ products. Its net profit in 
each case is the sum of its operational profits minus the fixed cost $K$. More precisely, for a particular type of communication, the operational profit of a product $j$ is the equal to the number of communications of type $j$ times the operating margin, that is, the price $p_{j}$ minus the (constant) marginal cost $c_{j} .{ }^{31}$ Thus, the net profit of the Vodacom firm for voice or SMS is ${ }^{32}$

$$
\Pi=\sum_{k=1}^{J}\left(p_{j}-c_{j}\right) q_{j}(p)-K
$$

The Vodacom firm chooses the price of its products that maximizes its profits, knowing that a price increase on product $j$, increases profits according to the level of sales, while at the same time reduces the sales of product $j$ proportionally to the markup

$$
m u_{j}=\left(p_{j}-c_{j}\right) / p_{j}
$$

In addition, the multiproduct firm takes into account the diversion ratio, that is, the fraction of lost sales of a certain product due to a price increase, that are recaptured by increases in sales on other products of the firm. In summary, the J first order conditions of our multiproduct firm for voice or SMS are $^{33}$

$$
q_{j}+\left(p_{j}-c_{j}\right) \frac{\partial q_{j}}{\partial p_{j}}+\sum_{\forall k-j}\left(p_{k}-c_{k}\right) \frac{\partial q_{k}}{\partial p_{j}}, \quad J=1, . ., 4
$$

If we rearrange this expression with equations (2) and (3), and solve the J-equation system, we have the following supply equation for the multinomial

\footnotetext{
${ }^{31} \mathrm{We}$ assume a constant returns to scale industry. Indeed, the physical components are relatively accessible as compared to the fixe-line industry, and the variable network costs are fairly constant and low up to the capacity constraints. We acknowledge however, that this matter is not yet a settled debate in the cellular industry. For example, McKenzie and Small (1997) find decreasing returns to scale in general and constant returns for the smallest firms, while Beauvais and Foreman (1999) find positive economies of scale though weaker than in the fixed-line industry.

${ }^{32}$ We are assuming separable costs and dependent demand functions, $q_{j}(p)$, where $p$ is the vector of prices.

${ }^{33}$ We choose to model a profit maximizing monopoly due to the lack of data on Vodacom's competitors. It should be a relatively fair approximation since Vodacom has the largest market share, and there is evidence that the firms are behaving non competitively. We should nevertheless put forward that demand under competition shall be more elastic than under monopoly. Indeed, the demand curve faced by a firm in a competitive environment is more price sensitive than the demand curve faced by a monopoly, i.e., the market demand curve.
} 
logit specification

$$
p_{j}=c_{j}+\frac{1}{\alpha\left(1-\sum_{k=1}^{J} s_{k}\right)}+\omega_{j}
$$

where $\omega_{j}$ is the disturbance term that captures unobserved product characteristics. By construction, estimation of equation (12) can be potentially plagued by endogeneity coming through the correlation between $s_{j}$ and $\omega_{j}$, and so has to be solved jointly with the demand equation.

\subsection{Calibration}

Regarding the joint estimation of the demand and supply equations (5) and (12), we solve the system through a calibration procedure. ${ }^{34}$ We have eight equations and nine unknowns, $\left\{\alpha, c_{i}, \psi_{i}\right\}$ for $i=1,2,3,4$. We propose then the following procedure based on some distributional assumptions:

1. We generate $\mathrm{K}$ times two vectors of four components for the own-price elasticity $\eta_{j, j}$ and the marginal costs $c_{j}$, where $\eta_{j, j} \sim N(0,1)$ and $c_{j} \sim$ $N(a, b)$ being $a$ the mean, which we define as the minimum price, and $b$ the standard deviation, which we define as the difference between the maximum price and the minimum price. In order to derive $\alpha$ we estimate jointly through the Non Linear Three Stage Least Squares (N3SLS) methodology the own-price elasticity and supply equations, (7) and (12), under the constraints. ${ }^{35}$

$$
\begin{gathered}
p_{j} \geq c j \quad \forall j \Rightarrow \alpha \geq 0 \\
c j \geq 0 \quad \forall j \Rightarrow \alpha \geq \frac{1}{p_{j}\left(1-\Sigma_{\forall k-1} s_{k}\right)} \quad \forall j
\end{gathered}
$$

\footnotetext{
${ }^{34}$ Once the data has been aggregated we only have points points per equation to derive the estimation.

${ }^{35}$ Estimations of the own-price elasticity equation under Ordinary Least Squares (OLS) gave systematically underestimated values of the sensitivity of utility to price, $\alpha$. Berry (1994) similarly finds underestimated and sometimes positive coefficients on prices under OLS, while reasonable estimates with instrumental variables. He argues that under OLS estimates of $\alpha$, the firm is pricing on the inelastic part of the demand curves, and thus results contradicting economic theory are possible. Therefore, we are only going to report the N3SLS regressions estimates in the remainder of the paper. The Full Information Maximum Likelihood (FIML) is not applicable since in some cases $\delta_{j}<0$ and then the random term $\xi_{j}$ does not follow a standard normal distribution.
} 
2. We derive the marginal costs, $c_{j}$, from the supply equation (12).

3. We derive the quality indices, $\psi_{i}$, from the demand equation (5).

4. We derive demand related results, namely, the consumer surplus in equation (6) and the own-price and cross-price elasticities in equations (7) and (8) and cost related results, namely, the markups in equation (11).

5. The process 1-4 is repeated for each of the values of the potential market factor $\mathrm{r}$.

\subsection{Results}

In this subsection, we report the results of the calibration procedure for the demand-and-supply system of equations in the case of voice and SMS communications. In particular, we report the sensitivity of utility to price, the cost related results, namely, the marginal costs and the markups, and the demand related results, namely, the quality indices, the consumer surplus, and the own-price and cross-price elasticities. We perform a sensitivity analysis by applying the procedure to different values of the market potential factor $r$, that is, to different shares of the outside good. We also provide results for the different types of samples, that is, for the total sample, and for the sub-samples of urban and rural consumers.

The preliminary empirical analysis of the data performed in section three sets the ground for the selected demand-and-supply system of equations. Let us briefly recall the different steps and outcomes of these analyses. First, we find that voice and SMS communications are associated with significantly different socio-economic characteristics, pricing scheme and sample pattern, which favors a separate analysis of these two options. Second, we derive for voice and SMS communications the set of five products contingent on the hour of the communication and on the type of correspondent, namely, Vodacom-Telkom/peak, Vodacom-Telkom/off-peak, CellC-MTN/peak, CellCMTN/off-peak and we also consider an outside option.

Third, our preliminary empirical analysis lead us to think that there is a selectivity bias on the total sample, towards the African dominant population areas. When it comes to exploring urban and rural sub-samples however, 
there is no severe problem of sample selection and therefore, this allows an unbiased comparison of the sub-samples. Lastly, we find that differences between the urban and rural sub-samples in terms of income levels, income correlation with voice and SMS communications, and behavior in terms of usage, motivate a separate analysis of these sub-samples, which may be considered as rough approximations to the first and second economies in South Africa.

Concerning our econometric framework, in order to perform the sensitivity analysis we consider three scenarios contingent on the value of the potential market factor $r$. First, a scenario where $r=0.5$, that is, the potential market size is fifty percent larger than the observed market size. Indeed, in our Vodacom data set consumers express their willingness to make a call by sending around 30\% free SMS with the text "Please Call Me" as compared to the around $60 \%$ voice communications in the total number of incoming communications. ${ }^{36}$ Second, two additional scenarios where we assume more conservative values $r=2$ and $r=4$, that is, the potential market size is two and four hundred percent larger than the observed market size, respectively. These latter values aim at accounting for the possibility that there exists a relatively large potential demand constrained by prices as put forward by the ICASA report. The suitability of these selected potential market factors is discussed below.

We proceed to analyze the calibration procedure results for voice and SMS communications, which allows us to estimate own-price and cross-price elasticities for prepaid consumers in South Africa. We make use of the demandand-supply system of equations which is based on the joint N3SLS estimation of equations (7) and (12), where the parameters to be estimated are $\left\{\alpha, c_{j}, \psi_{j}\right\} .{ }^{37}$ The observed variables are the prices $p_{j}$, and the market shares $s_{j}$. The disturbance terms are the unobserved product characteristics $\xi_{j}$ and $\omega_{j}$. In Tables 9 and 10, we report the calibration estimates for the potential market factors, $r=0.5, r=2$ and $r=4$, and for the total sample, and the urban and rural sub-samples. These tables show the estimated value of the sensitivity of utility to price, $\alpha$, the cost related results, namely, the marginal

\footnotetext{
${ }^{36}$ The "Please Call Me" service enables Vodacom subscribers to request a call with up to five free SMS per day.

${ }^{37}$ All of the specifications have an homoskedastic error structure, since the presence of heteroskedasticity is always rejected at the one percent.
} 
$\operatorname{costs} c_{j}$ and the markups $m u_{j}$, and the demand related results, namely, the quality indices $\psi_{j}$, the net consumer surplus $C S$, and the own-price and cross-price elasticities $\eta_{j, j}$ and $\eta_{j, k}$.

Regarding the estimates of the sensitivity of utility to price $\alpha$ in Tables 9 and 10, we recall this is the first parameter to be estimated through our calibration procedure (see subsection 4.3). Following the first step of this procedure we perform the N3SLS joint estimation of the own-price elasticity and supply equations under the constraints (13) and (14). While the constraint (13) is not binding since we can see in the tables that $\alpha>0$, the constraint (14) instead always binds, that is, in all cases $c_{i}=0$ for some $i$. Therefore, $\alpha$ is given by $1 /\left(p_{\min }\left(1-\sum_{\forall k-1} s_{k}\right)\right)$, which in practice corresponds to $1 /\left(p_{2}\left(1-\sum_{\forall k-1} s_{k}\right)\right)$ for voice, and $1 /\left(p_{\{2,4\}}\left(1-\sum_{\forall k-1} s_{k}\right)\right)$ for SMS (see Tables 5 and 6 ).

A casual look at the tables reveals the following information about $\alpha$. First, we see that as $r$ increases, $\alpha$ decreases. That is, as the potential market factor increases, the sensitivity of utility to price decreases. Second, since the minimum price is lower for SMS than for voice (0.35 as compared to around 1.08), the sensitivity of utility to price is larger for SMS than for voice, as much as three times. Third, since in the case of SMS the minimum price is the same for all prepaid cards (4UP, VGO, VSS), $\alpha$ is the same for the total sample, and the urban and rural sub-samples. However, in the case of voice each prepaid card charges a different price and hence, the mean of the minimum prices differs between the urban and the rural sub-samples. This figure is higher for the urban than for the rural sub-sample and therefore, the sensitivity of utility to price is lower for urban than for rural consumers.

We proceed to analyze the cost related results. By observing the marginal cost estimates, we first note that $c_{2}=0$ for voice and $c_{2}=c_{4}=0$ for SMS. Indeed, as we already explained the constraint (14) binds for those products offering the lowest prices that is, for consumers placing a voice call during off-peak hours towards Vodacom or Telkom users, and for consumers sending an SMS during off-peak hours towards any operator. This finding is consistent with costs depending on traffic congestion where in general lower costs are associated with off-peak periods. ${ }^{38}$ We would nevertheless expect

\footnotetext{
${ }^{38}$ Notice however that since currently Vodacom has set tariffs with a large enough gap between peak and off-peak periods to smooth out the network load over the day, network
} 
that marginal costs in cellular networks are above zero to some extent. ${ }^{39}$

Furthermore, we can see in the tables that the marginal costs are higher for voice than for SMS, around three times more. Indeed, reserving a real time end-to-end communication shall be more onerous than the transmission of a message through the network. In Table 9 for voice communications we also observe that marginal costs are slightly higher for rural than for urban consumers. This is consistent with rural consumers placing many more (low price) calls than urban consumers (see Table 8) and therefore with higher levels of congestion in rural networks. In addition, rural consumers place more long distance calls than urban consumers, towards those metropolitan areas where services and employment are available. Higher operational service costs should also be expected in relation to urban sites. Finally, also in Table 9 we see that marginal costs associated with making a voice call towards other mobile networks are higher than towards Vodacom or Telkom.

The analysis of the markups, $m u_{j}$, is then straight forward. We see that markups are high for voice and SMS services with values in the range of $\{0.366,1\}$ for voice and $\{0.437,1\}$ for SMS. The markups are the largest for the off-peak hours when marginal costs are zero or close to zero, with values between $\{0.821,1\}$. In addition, the markups associated with SMS are slightly larger than those associated with voice. For example, for the total sample the markup for peak hours is around 0.36 for voice, while 0.47 for SMS. In accordance with the lower marginal costs for voice for urban consumers as compared to rural consumers, the markup of urban consumers is slightly higher. Also in the case of voice, the markups associated with calls made towards Vodacom or Telkom are higher than those associated with the other mobile operators, CellC and MTN.

We now proceed to explore the demand related results in Tables 9 and 10. Starting with the quality index, $\psi_{i}$, one very visible result is that this index

busy hours often occur during the off-peak period.

${ }^{39}$ In a cellular network, once geographical coverage has been achieved, virtually all network elements are dimensioned for capacity. As traffic increases (given a fixed amount of radio spectrum), the network operator needs to build more radio sites, and install more core network capacity. Therefore, marginal costs of a mobile network are expected to be higher than those of a long distance fixed-line network where only some elements are dimensioned for capacity, and which in turn are higher than those of a local fixed-line network where costs are fixed irrespective of capacity (and where marginal costs would be close to zero). 
is much larger for peak than for off-peak hours, specially for voice where the ratio is around three to one. All consumers (urban and rural) are attaching a greater value to communications during peak hours. Moreover, the values of the quality index decrease as the potential market factor $r$ increases. Indeed, as the utility of the outside good increases with respect to the inside goods, the value attached to inside goods decreases. We also observe that the quality index is in general higher for voice than for SMS, specially during peak hours. Indeed, the number of voice calls is 10 to 20 times larger than the number of SMS in our data set (see Table 7).

If we compare sub-samples, we appreciate that the quality index during peak hours is larger for rural than for urban consumers. Relatedly, the quality index during off-peak hours is larger for urban than for rural consumers. Hence, as we already highlighted in our preliminary study rural consumers have a larger preference than urban consumers for peak hours, while urban consumers have a larger preference than rural consumers for off-peak hours (see Table 8). We can also analyze the quality index according to the type of correspondent. For SMS in Table 10, the quality index is larger for messages sent towards Vodacom than towards the other mobile operators. Indeed, in Tables 7 and 8 we can see that between 1.5 and two times more SMS sent to Vodacom than to CellC or MTN. For Voice in Table 9, the analysis differs. While the quality index during peak hours is larger when reaching a Vodacom user than other mobile operator users, this index during off-peak hours is larger when reaching other mobile operator users than when calling a Vodacom user. This is driven by the fact that prices during off-peak hours are slightly higher for voice calls towards CellC or MTN as compared to Vodacom or Telkom (see Table 5).

The least we can say is that the values of the net consumer surplus, $C S$, are quite low with the values in the range of $\{0.06,0.39\}$. We see that the $C S$ decreases as the potential market factor $r$ increases. Again, an increase in $r$ implies that the utility of the outside good increases with respect to the inside goods and therefore, the net consumer surplus associated with the inside goods decreases. The net consumer surplus is larger for voice than for SMS, as much as three times. This reflects the larger preference for voice than for SMS communications (see Table 7) despite the larger prices attributed to 
voice calls (see Tables 5 and 6 ). When we compare across urban and rural sub-samples, we observe that the net consumer surplus is almost the same in both cases.

In Tables 9 and 10 below, we also report for prepaid Vodacom consumers the own-price and cross-price elasticities, $\eta_{j, j}$ and $\eta_{j, k}$, which depend upon the values of the sensitivity of utility to price $\alpha$, and the potential market factor $r$. We see that own-price elasticities are negative as expected, that is, a price increase in a product decreases the associated number of communications. We observe that the demand for both voice and SMS is very price sensitive. Hence, this corroborates our conjecture that demand for cellular services in South Africa is elastic, that is, as price increases by one percent consumption is in all cases reduced by more than one percent. This holds true even for the lowest own-price elasticities associated with the largest potential market factor $r=4 .^{40}$ In addition, the own-price elasticities we find appear to be higher than those associated with developed countries. For example, for $r=2$ the own-price elasticities are in the range of $\{-3.6,-1.3\}$ for voice, and $\{-3.2,-1.2\}$ for SMS.

We also remark from the values of $\eta_{j, j}$ that own-price elasticities are larger for voice than for SMS communications for a given $r$. Despite the larger sensitivity of utility to price for SMS as compared to voice, this difference is not enough to compensate the larger prices associated with voice as compared to SMS. Next, these Tables 9 and 10 reveal that own-price elasticities of communications during peak hours are much larger than those during off-peak hours, as much as three times. This holds for voice and SMS communications, and for the total sample, and the urban and rural sub-samples. If we take in Table 9 for $r=2$ and the total sample, an increase of one percent in price, would decrease demand for calling Vodacom or Telkom consumers during peak hours by $3.6 \%$, while the demand for calling these same type of consumers during off-peak hours would decrease by $1.3 \%$. Indeed, prices are significantly higher during peak hours than during off-peak hours for voice and SMS (see Tables 5 and 6) and as consequence demand for peak hours

\footnotetext{
${ }^{40}$ Both for voice and SMS communications, own-price elasticities decrease as $r$ increases providing us with a range of elasticity values contingent on the number of users that are not using the offered service. We believe there is no need to test for larger values of the potential market factor since already with $r=4$ the own-price and cross-price elasticities are converging.
} 
communications is much more elastic than for off-peak hours.

We can also see that own-price elasticities of those communications made towards CellC or MTN consumers are higher than those made towards Vodacom or Telkom consumers. This holds true for voice and SMS communications and for the total sample, and the urban and rural sub-samples. Nevertheless, the differences in elasticities are not large and are admittedly smaller than those observed when comparing communications made during peak vs off-peak hours. Indeed, in Table 9 for $r=2$ and the total sample, an increase of one percent in price decreases calls made during off-peak hours to CellC or MTN users by $1.7 \%$, while the fall would be of $1.3 \%$ for Vodacom or Telkom consumers. This is due to the slightly lower prices associated with calls made towards Vodacom or Telkom users as compared to those made towards CellC or MTN users (see Table 5) and to the fact that Vodacom consumers make systematically around twice as many voice communications towards Vodacom or Telkom than towards CellC or MTN users, that is, the mean valuation of making a call towards Vodacom or Telkom is larger than towards the other cellular operators. On the other hand, there are no price differences between sending an SMS to Vodacom and sending it to other cellular operator users. For SMS, differences in own-price elasticities according to the type of correspondent are explained by the fact that there is a larger number of SMS being sent towards Vodacom than towards the other cellular operators. ${ }^{41}$

When analyzing the sub-samples of voice and SMS communications, we observe that own-price elasticities when communicating during peak hours are larger in the urban than in the rural sub-sample. Indeed, in Table 9 for $r=2$ a one percent price increase when calling a Vodacom or Telkom correspondent during peak hours, causes a fall in demand of $3.7 \%$ in the urban sub-sample as compared to $3.5 \%$ in the rural sub-sample. In contrast, ownprice elasticities when communicating during off-peak hours are larger for the rural than for the urban sub-sample. Following the previous example, a one percent price increase when calling a Vodacom or Telkom correspondent during off-peak hours, causes a fall in demand of $1.2 \%$ in the urban sub-

\footnotetext{
${ }^{41}$ This could be simply explained by the fact that Vodacom has around twice more consumers than the other two cellular competitors by 2005 .
} 
sample as compared to $1.3 \%$ in the rural sub-sample. ${ }^{42}$ Hence, these results partly corroborate our conjecture that price elasticities are lower for rural consumers. In that sense demand is less elastic for rural than for urban consumers during peak hours which reflects, among other things, that major services and labor opportunities are concentrated in cities. It may reflect as well the absence of adequate transportation networks, and the greater time loses associated with travel. In contrast, demand is more elastic for rural than for urban consumers during off-peak hours which in turn reflects that rural consumers are less prone to use cellular phones for leisure.

From Tables 9 and 10, we observe that cross-price elasticities are positive as expected among substitutable products, that is, an increase in the price of a product increases the consumption of other products. We are using a rigid substitution scheme based on multinomial logit as we can see for example in Table 9 for $r=2$ and the total sample, where a one percent price increase when calling a Vodacom or Telkom user during peak hours would increase the number of calls made to these operators during off-peak hours and to CellC or MTN users during peak or off-peak hours, by the same $0.4 \%$ factor. Obviously, taking into account our preliminary analysis on prices and sample patterns, this is rather simplistic but is allows however, to draw some qualitative conclusions from our results.

If we proceed to analyze cross-elasticities comparing peak vs off-peak hours, we observe for voice communications (see Table 9) that these are larger for changes in peak hours prices $\left\{\eta_{j, 1}, \eta_{j, 3}\right\}$, as compared to changes in off-peak hours prices $\left\{\eta_{j, 2}, \eta_{j, 4}\right\}$, specially in the rural sub-sample. This is driven by the fact that prices are much larger during peak hours (see Table 5) and that rural consumers have a larger preference for peak hours (see Table 8). However, this pattern does not hold true when analyzing voice communications in the urban sub-sample with calls towards CellC or MTN users. In this case, the larger prices attributed to peak hours than to offpeak hours are not enough to compensate the large number of calls placed during off-peak hours and thus, the situation is inverted. In the urban sub-

\footnotetext{
${ }^{42}$ This is consistent with the information in Table 8 where we see that urban consumers always place more calls during off-peak hours, while rural consumers give a larger mean valuation to peak hours, despite the higher prices associated with this time frame. Notice we have taken $r=2$ as example, and that the differences between price elasticities in urban and rural sub-samples grow for larger values of the potential market factor. Moreover, these differences are systematic both for voice and SMS services.
} 
sample for voice communications towards CellC and MTN correspondents, cross-price elasticities are larger when the price of off-peak rather than of peak hours changes.

If we now focus on analyzing cross-elasticities comparing peak vs offpeak hours but this time for SMS communications (see Table 10), we see that for the total sample, the situation is the reverse to the one described for voice communications. The cross-price elasticities are larger with changes in the price for off-peak hours as compared to peak hours. The story here is explained through two features. First, the price differences are not as large for SMS as for voice calls, when comparing peak and off-peak hours (see Tables 5 and 6). Second and most importantly, the urban sub-sample has much more weight than the rural sub-sample in SMS as compared to voice communications and thus, since urban users are sending many more SMS during off-peak hours than rural users, they are then driving the results of the total sample. Indeed, we retrieve the same pattern when analyzing the urban sub-sample for SMS that is, cross-price elasticities are larger with changes in the price for off-peak as compared to peak hours. However, when it comes to the rural sub-sample, we find instead that cross-price elasticities are larger with changes in the price for peak hours as compared to off-peak hours. Indeed, there are not as many SMS sent during off-peak hours as in the urban sub-sample and hence, this weaker valuation of off-peak hours is not enough to compensate larger prices during peak hours. To summarize then, both for voice and SMS cross-elasticities are larger with changes in prices for peak hours as compared to off-peak hours in the rural sub-sample, while the reverse can be said for the urban sub-sample.

Cross-price elasticities are larger with changes in the price of reaching Vodacom-Telkom users $\left\{\eta_{j, 1}, \eta_{j, 2}\right\}$, as compared to reaching CellC or MTN users $\left\{\eta_{j, 3}, \eta_{j, 4}\right\}$. This holds for voice and SMS, and for the total sample, and the urban and rural sub-samples. This feature is mainly due to the larger market shares and thus the larger mean valuation associated with consumers communicating towards Vodacom and Telkom users, with respect to CellC and MTN users. The price differences are not playing an important role in this matter, since given a particular time frame these are quite similar for voice and equal for SMS (see Tables 5 and 6). Moreover, if we compare 
directly urban and rural sub-samples, we see that cross-price elasticities for changes in peak hours prices are larger for rural than for urban consumers. On the other hand, cross-price elasticities for changes in off-peak hours prices are larger for urban than for rural users. These results obviously only reflect the different preferences of consumers, where rural users are placing more communications during peak hours and urban consumers during off-peak hours.

To summarize, our empirical analysis of the data set supports the proposition that demand for cellular services is very sensitive to changes in price, with larger price elasticities than those typically found in developed countries. Every own-price elasticity is above the unity which implies that, without capacity constraints, a decrease in price will cause an increase in revenue to the company, since the increase in quantity is quite larger than the change in price. Moreover, we also give empirical substance to the conjecture that urban demand for cellular services is more elastic than rural demand but this only holds true during peak hours, that is, urban users are much more sensitive to changes in prices during this time frame. However, we find that rural demand for cellular services is more elastic than urban demand during off-peak hours. In the same vein, the quality index is larger for rural than for urban consumers during peak hours, while it is larger for urban than for rural consumers during off-peak hours. Overall, results put forward that in relative terms rural consumers have a higher preference for working hours, while urban consumers for leisure hours. Next, for the same market factor, own-price elasticities are larger for voice than for SMS, which is associated to the larger prices of voice calls.

We also find that communications made during peak hours are much more elastic than those made during off-peak hours, which is strongly driven by the large prices associated with peak hours. In addition, for all consumers (urban and rural) the quality index associated with peak hours is much larger than that associated with off-peak hours. When it comes to cross-price elasticities we find that overall for rural consumers cross-price elasticities are larger with changes in prices for peak hours as compared to off-peak hours, reflecting the larger prices and stronger preference for peak hours, while for urban consumers cross-price elasticities are larger with changes in prices for 
Table 9

Calibration estimates for Voice

\begin{tabular}{|c|c|c|c|c|c|c|c|c|c|}
\hline \multirow{2}{*}{\multicolumn{4}{|c|}{$\begin{array}{l}\text { Total SAMPLe } \\
\diamond \text { Potential market factor }\end{array}$}} & \multicolumn{3}{|c|}{ URBAN SUB-SAMPLE } & \multicolumn{3}{|c|}{ RURAL SUB-SAMPLE } \\
\hline & & & & & & & & & \\
\hline $\mathrm{r}$ & 0.5 & 2 & 4 & 0.5 & 2 & 4 & 0.5 & 2 & 4 \\
\hline \multicolumn{10}{|c|}{$\diamond$ Sensitivity of utility to price } \\
\hline$\alpha$ & 2.764 & 1.380 & 1.152 & 2.752 & 1.376 & 1.146 & 2.764 & 1.380 & 1.152 \\
\hline \multicolumn{10}{|c|}{$\begin{array}{l}\text { COST RELATED RESUlTS } \\
\diamond \text { Marginal cost }\end{array}$} \\
\hline $\begin{array}{l}c_{1} \\
c_{2} \\
c_{3} \\
c_{4}\end{array}$ & & $\begin{array}{c}1.876 \\
0 \\
1.894 \\
0.235\end{array}$ & & & $\begin{array}{l}1.846 \\
0 \\
1.883 \\
0.226\end{array}$ & & & $\begin{array}{l}1.876 \\
0 \\
1.894 \\
0.235\end{array}$ & \\
\hline \multicolumn{10}{|c|}{$\diamond$ Mark up } \\
\hline $\begin{array}{l}m u_{1} \\
m u_{2} \\
m u_{3} \\
m u_{4}\end{array}$ & & $\begin{array}{c}0.366 \\
1 \\
0.364 \\
0.821\end{array}$ & & & $\begin{array}{c}0.371 \\
1 \\
0.366 \\
0.828\end{array}$ & & & $\begin{array}{c}0.366 \\
1 \\
0.364 \\
0.821\end{array}$ & \\
\hline \multicolumn{10}{|c|}{$\begin{array}{l}\text { DEMAND RELATED RESULTS } \\
\diamond \text { Quality }\end{array}$} \\
\hline $\begin{array}{l}\psi_{1} \\
\psi_{2} \\
\psi_{3} \\
\psi_{4}\end{array}$ & $\begin{array}{l}7.741 \\
2.539 \\
7.113 \\
2.731\end{array}$ & $\begin{array}{c}2.257 \\
-0.364 \\
1.605 \\
-0.481\end{array}$ & $\begin{array}{c}0.888 \\
-1.306 \\
0.232 \\
-1.475\end{array}$ & $\begin{array}{l}7.215 \\
2.854 \\
6.569 \\
2.940\end{array}$ & $\begin{array}{c}1.789 \\
-0.021 \\
1.092 \\
-0.256\end{array}$ & $\begin{array}{c}0.421 \\
-0.965 \\
-0.283 \\
-1.251\end{array}$ & $\begin{array}{l}7.853 \\
2.401 \\
7.238 \\
2.638\end{array}$ & $\begin{array}{c}2.367 \\
-0.485 \\
1.730 \\
-0.574\end{array}$ & $\begin{array}{c}0.999 \\
-1.426 \\
0.357 \\
-1.568\end{array}$ \\
\hline \multicolumn{10}{|c|}{$\diamond$ Consumer surplus } \\
\hline $\begin{array}{l}\mathrm{CS} \\
\diamond \mathrm{O}\end{array}$ & $\begin{array}{l}0.396 \\
\text {-price }\end{array}$ & $\begin{array}{l}0.291 \\
\text { asticity }\end{array}$ & 0.191 & 0.399 & 0.294 & 0.193 & 0.397 & 0.293 & 0.192 \\
\hline $\begin{array}{l}\eta_{1,1} \\
\eta_{2,2} \\
\eta_{3,3} \\
\eta_{4,4}\end{array}$ & $\begin{array}{l}-6.440 \\
-2.364 \\
-7.338 \\
-3.162\end{array}$ & $\begin{array}{l}-3.650 \\
-1.339 \\
-3.889 \\
-1.701\end{array}$ & $\begin{array}{l}-3.277 \\
-1.170 \\
-3.332 \\
-1.459\end{array}$ & $\begin{array}{l}-6.945 \\
-2.126 \\
-7.641 \\
-3.013\end{array}$ & $\begin{array}{l}-3.757 \\
-1.282 \\
-3.955 \\
-1.658\end{array}$ & $\begin{array}{l}-3.223 \\
-1.140 \\
-3.342 \\
-1.432\end{array}$ & $\begin{array}{l}-6.233 \\
-2.448 \\
-7.219 \\
-3.205\end{array}$ & $\begin{array}{l}-3.599 \\
-1.361 \\
-3.860 \\
-1.712\end{array}$ & $\begin{array}{l}-3.169 \\
-1.181 \\
-3.305 \\
-1.465\end{array}$ \\
\hline \multicolumn{10}{|c|}{$\diamond$ Cross-price elasticity } \\
\hline $\begin{array}{l}\eta_{j, 1} \\
\eta_{j, 2} \\
\eta_{j, 3} \\
\eta_{j, 4}\end{array}$ & $\begin{array}{l}1.751 \\
0.631 \\
0.895 \\
0.486\end{array}$ & $\begin{array}{l}0.437 \\
0.157 \\
0.221 \\
0.120\end{array}$ & $\begin{array}{l}0.218 \\
0.078 \\
0.109 \\
0.060\end{array}$ & $\begin{array}{l}1.134 \\
0.869 \\
0.539 \\
0.608\end{array}$ & $\begin{array}{l}0.282 \\
0.217 \\
0.137 \\
0.152\end{array}$ & $\begin{array}{l}0.141 \\
0.108 \\
0.064 \\
0.075\end{array}$ & $\begin{array}{l}1.953 \\
0.550 \\
1.014 \\
0.442\end{array}$ & $\begin{array}{l}0.487 \\
0.136 \\
0.251 \\
0.109\end{array}$ & $\begin{array}{l}0.242 \\
0.068 \\
0.126 \\
0.054\end{array}$ \\
\hline
\end{tabular}


Table 10

Calibration estimates for SMS

\begin{tabular}{|c|c|c|c|c|c|c|c|c|c|}
\hline \multirow{2}{*}{\multicolumn{4}{|c|}{$\begin{array}{l}\text { Total SAmple } \\
\diamond \text { Potential market factor }\end{array}$}} & \multicolumn{3}{|c|}{ URBAN SUB-SAMPLE } & \multicolumn{3}{|c|}{ RURAL SUB-SAMPLE } \\
\hline & & & & & & & & & \\
\hline $\mathrm{r}$ & 0.5 & 2 & 4 & 0.5 & 2 & 4 & 0.5 & 2 & 4 \\
\hline \multicolumn{10}{|c|}{$\diamond$ Sensitivity of utility to price } \\
\hline$\alpha$ & 8.571 & 4.286 & 3.571 & 8.571 & 4.286 & 3.571 & 8.571 & 4.286 & 3.571 \\
\hline \multicolumn{10}{|c|}{$\begin{array}{l}\text { COST RELATED RESULTS } \\
\diamond \text { Marginal cost }\end{array}$} \\
\hline $\begin{array}{l}c_{1} \\
c_{2} \\
c_{3} \\
c_{4}\end{array}$ & & $\begin{array}{c}0.450 \\
0 \\
0.450 \\
0\end{array}$ & & & $\begin{array}{c}0.450 \\
0 \\
0.450 \\
0\end{array}$ & & & $\begin{array}{c}0.450 \\
0 \\
0.450 \\
0\end{array}$ & \\
\hline \multicolumn{10}{|c|}{$\diamond$ Mark up } \\
\hline $\begin{array}{l}m u_{1} \\
m u_{2} \\
m u_{3} \\
m u_{4}\end{array}$ & & $\begin{array}{c}0.437 \\
1 \\
0.437 \\
1\end{array}$ & & & $\begin{array}{c}0.437 \\
1 \\
0.437 \\
1\end{array}$ & & & $\begin{array}{c}0.437 \\
1 \\
0.437 \\
1\end{array}$ & \\
\hline \multicolumn{10}{|c|}{$\begin{array}{l}\text { DEMAND RELATED RESULTS } \\
\diamond \text { Quality }\end{array}$} \\
\hline $\begin{array}{l}\psi_{1} \\
\psi_{2} \\
\psi_{3} \\
\psi_{4}\end{array}$ & $\begin{array}{l}5.743 \\
2.864 \\
5.382 \\
2.426\end{array}$ & $\begin{array}{c}0.936 \\
-0.019 \\
0.574 \\
-0.458\end{array}$ & $\begin{array}{l}-0.328 \\
-0.963 \\
-0.691 \\
-1.402\end{array}$ & $\begin{array}{l}5.579 \\
2.933 \\
5.288 \\
2.449\end{array}$ & $\begin{array}{c}0.765 \\
0.048 \\
0.474 \\
-0.437\end{array}$ & $\begin{array}{l}-0.500 \\
-0.897 \\
-0.791 \\
-1.381\end{array}$ & $\begin{array}{l}6.021 \\
2.714 \\
5.563 \\
2.383\end{array}$ & $\begin{array}{c}1.207 \\
-0.171 \\
0.749 \\
-0.502\end{array}$ & $\begin{array}{l}-0.059 \\
-1.115 \\
-0.516 \\
-1.446\end{array}$ \\
\hline \multicolumn{10}{|c|}{$\diamond$ Consumer surplus } \\
\hline \multicolumn{9}{|c|}{$\diamond$ Own-price elasticity } & 0.062 \\
\hline $\begin{array}{l}\eta_{1,1} \\
\eta_{2,2} \\
\eta_{3,3} \\
\eta_{4,4}\end{array}$ & $\begin{array}{l}-6.102 \\
-2.126 \\
-6.335 \\
-2.435\end{array}$ & $\begin{array}{l}-3.240 \\
-1.282 \\
-3.298 \\
-1.359\end{array}$ & $\begin{array}{l}-2.762 \\
-1.141 \\
-2.791 \\
-1.179\end{array}$ & $\begin{array}{l}-6.225 \\
-2.066 \\
-6.383 \\
-2.423\end{array}$ & $\begin{array}{l}-3.271 \\
-1.267 \\
-3.312 \\
-1.356\end{array}$ & $\begin{array}{l}-2.779 \\
-1.133 \\
-2.799 \\
-1.178\end{array}$ & $\begin{array}{l}-5.869 \\
-2.249 \\
-6.232 \\
-2.462\end{array}$ & $\begin{array}{l}-3.181 \\
-1.312 \\
-3.274 \\
-1.366\end{array}$ & $\begin{array}{l}-2.733 \\
-1.156 \\
-2.779 \\
-1.183\end{array}$ \\
\hline \multicolumn{10}{|c|}{$\diamond$ Cross-price elasticity } \\
\hline $\begin{array}{l}\eta_{j, 1} \\
\eta_{j, 2} \\
\eta_{j, 3} \\
\eta_{j, 4}\end{array}$ & $\begin{array}{l}0.754 \\
0.872 \\
0.521 \\
0.563\end{array}$ & $\begin{array}{l}0.188 \\
0.217 \\
0.130 \\
0.141\end{array}$ & $\begin{array}{l}0.094 \\
0.108 \\
0.060 \\
0.069\end{array}$ & $\begin{array}{l}0.603 \\
0.932 \\
0.473 \\
0.576\end{array}$ & $\begin{array}{l}0.157 \\
0.232 \\
0.116 \\
0.144\end{array}$ & $\begin{array}{l}0.077 \\
0.116 \\
0.057 \\
0.071\end{array}$ & $\begin{array}{l}0.987 \\
0.749 \\
0.623 \\
0.536\end{array}$ & $\begin{array}{l}0.246 \\
0.187 \\
0.154 \\
0.133\end{array}$ & $\begin{array}{l}0.122 \\
0.093 \\
0.077 \\
0.066\end{array}$ \\
\hline
\end{tabular}

off-peak hours as compared to peak hours, because of their larger preference or mean valuation for off-peak hours. Finally, we observe that demand for communications towards CellC or MTN users is more elastic than that towards Vodacom or Telkom users, though the difference is much smaller than when comparing peak and off-peak communications. This situation is not 
really explained through prices which are fairly similar when joining all correspondents, but is due to consumers preferences over Vodacom and Telkom correspondents, probably reflecting the larger consumer base of these companies. On the other hand, also because of the larger preference or mean valuation for communicating with Vodacom and Telkom, we find that the cross-price elasticities are larger for changes in the price of reaching Vodacom or Telkom users as compared to CellC or MTN.

\section{Conclusion}

A deeper understanding of demand for telecommunications services in the growing markets in developing countries is clearly appealing so that market organizations and regulatory institutions can better anticipate and adapt offer. Few empirical studies have however, explored this domain. In particular, there are, to our knowledge, no micro-econometric studies that analyze data stemming directly from operators. In this paper, we investigate price elasticities associated with voice and SMS cellular services using a cross-sectional data set on 6,936 Vodacom consumers. In the particular context of South Africa, we are concerned by the usage rather than the access to telecommunications since there is a very high degree of cellular penetration. ${ }^{43}$

Before summarizing our main findings, we want to highlight that our results could be biased since they are based on the assumption of a monopolistic market due to lack of data on Vodacom's competitors. It should be kept in mind therefore, that if Vodacom's demand had been modeled accounting for its competitors, we would have obtained more elastic price elasticities than under the monopolistic model. ${ }^{44}$ Moreover, due to the nature of the data and to the type of model used, we report long-run elasticities which are the ones used to decide on investment. ${ }^{45}$

Our empirical findings provide evidence that demand for cellular services is elastic, with higher price elasticities than those typically associated with

\footnotetext{
${ }^{43}$ We should acknowledge the fact that in developing countries cellular phone users often use more than one SIM card to avoid high interconnection fees. This phenomenon, which is not accounted for in our study, is however less an issue in South Africa than in other Sub-Saharan countries.

${ }^{44}$ Indeed, the demand curve faced by a firm in a competitive environment is more price sensitive than the demand curve faced by a monopoly, that is, the total demand curve.

${ }^{45}$ Short-run elasticities based on time series data are typically much smaller than longrun elasticities.
} 
developed countries. Cellular consumers are very sensitive to changes in prices, with own-price elasticities most commonly between -1.3 and -3.8 for voice and between -1.2 and -3.2 for SMS. ${ }^{46}$ In general terms, these results suggest that consumers are not only making use of the cellular phone for essential calls, where price elasticities would be rather small, but also for maintaining relationships, for convenience, or simply for leisure, with money being diverted from other non essential uses.

By far, the largest differences in our estimations are those between peak and off-peak hour services. Voice or SMS communications made during peak hours have a greater value for consumers, but since they are priced highly than off-peak hours, they are more than twice more elastic. This leads us to conclude that all subscribers (urban and rural) value the ability to place communications during working hours presumably for the purpose of economic activity.

We find that demand for joining CellC or MTN cellular consumers is more elastic than the demand for joining the fixed-line or Vodacom cellular consumers. However, this difference in elasticities is not as large as when comparing time frames, since prices are not as different when trying to communicate with different correspondents. Interconnection tariffs therefore, do not appear to account for the heaviest burdens in our data set.

We provide some empirical substance to the conjecture that price elasticities are lower for rural than for urban consumers, where this statement holds true in particular for peak hours. ${ }^{47}$ In contrast with this finding, we obtain that price elasticities are lower for urban than for rural consumers during off-peak hours. In the same vein, rural consumers attach a greater value than urban consumers to peak hours, while urban consumers attach a

\footnotetext{
${ }^{46}$ There are several illustrations that provide evidence of similarly large price elasticities for telecommunications services in developing countries. For example, when the cellular provider Celtel in Congo reduced tariffs between Kinshasa and Brazzaville by one third, the traffic increased ten times. In India, in the fixed-line, tariff reductions led to monthly revenues increasing by a factor of 2.6 between September 1999 and August 2000 at Parvathagiri Exchange in Andhra Pradesh.

${ }^{47}$ In general terms this argument can be explained by the cost of alternatives. The Canadian International Development Agency (CIDA) study on the village phone programme in rural Bangladesh, illustrates this idea. They find that the cost of the trip to the city is two to eight times higher than the cost of a single phone call, which implies significant savings for rural inhabitants. Similarly, in a Vodafone study on cellular users in Tanzania and South Africa, $50 \%$ to $70 \%$ of respondents claimed that their cellular phones led to large savings in travel time and cost.
} 
greater value than rural consumers to off-peak hours. Even if these urban vs rural differences are of second order in comparison with peak vs off-peak hours differences, results reveal that in relative terms rural consumers have a larger preference to use the cellular phone during working hours, while urban consumers during leisure hours.

There is a particular interest to compare consumption patterns of urban and rural consumers in the sample, as imperfect proxies for the so-called first and second economies in South Africa. Indeed, recent market liberalization policies in South Africa are under a broader program that is driven by the desire of diminishing the distance between these first and second economies. Our result on the preference of rural consumers for peak hours is consistent with the mismatch between the areas where people live and those where work opportunities exist, after decades of institutionalized discrimination. The white minority lives in areas where almost all economic activity is based, while the black majority lives either in a Bantustan, or a white-owned farm, or in a black township near a white town, with virtually no commercial or industrial activity and few opportunities for employment outside the informal sector.

As recognized by Van der Merwe (2006) the geographic distance between the places where the majority of people live, and those where businesses and work opportunities exist, makes searching for employment difficult and expensive. In order to reduce unemployment and poverty, the government faces the challenge of expanding the today narrow social networks that could lead to employment amongst black people, easing access to work opportunities. Our findings suggests that reducing the gap between the first and second economies in South Africa, calls for an encouragement of investment efforts in network availability in rural areas since usage in these areas appears to support economic activity as highlighted by the high value and relative low elasticity attached to working hours. These policy insights are consistent with the universal access objectives fixed by the South African authorities.

Together with the report of the South African regulator ICASA that states that voice and SMS cellular communications are heavily charged and more so in the case of prepaid consumers, the high elasticities we report lead us at first to suggest from a policy perspective that if market organizations 
or regulatory institutions were to set price cuts on prepaid services this could be rewarding both for consumers in terms of usage and for the firm in terms of its revenues, and more so during peak hours. ${ }^{4849}$ Indeed, it is due to the high prices in this time frame, that demand for peak hours is strongly more elastic than demand for off-peak hours. However, this suggestion suffers from two caveats.

Firstly, our data set is based on 2005 network information, while there have been some efforts on price reductions on behalf of Vodacom in the mean time. ${ }^{50}$ Secondly, though price reductions would increase revenue, they would also increase peak time usage which could eventually raise network capacity costs. Therefore, for the particular case of rural areas networks which are running close to full capacity, it would be necessary to verify that the increase in revenues would be sufficient to cover the eventual necessity of incremental investments on more base stations.

In summary, if market organizations and regulatory institutions were to react to the above specificities in terms of the high price elasticities and the urban vs rural patterns of consumption, features that can be probably extrapolated to other developing countries' experiences, an enhancement of both the firm's profit and the consumer welfare could be expected.

\footnotetext{
${ }^{48}$ Network operators do not necessarily agree with ICASA's statements.

${ }^{49}$ Prepaid prices are however, comparable to those charged in Europe. In France for example, the ratio of prepaid minute tariffs to average monthly income is not that different from that in South Africa. The purchasing level in absolute terms, which should be smaller in South Africa, must be then playing a major role in defining consumer preferences.

${ }^{50}$ By 2007 Vodacom prepaid cards tariffs include the so-called "happy hours" from $5 \mathrm{pm}$ to 8pm during the week. The company is also offering a new prepaid card with lower tariffs when placing a voice call towards other Vodacom consumers and during peak hours, at the cost of an annual subscription of 899 Rands.
} 


\section{References}

Aldebert, M., Ivaldi, M., and C. Roucolle, "Telecommunications demand and pricing structure: An econometric analysis," Telecommunication Systems, 25(1), 2004, pp. 89-115.

Beauvais, E., and R.D. Foreman, "Scale economies in cellular telephony: Size matters," Journal of Regulatory Economics, 16(3), 1999, pp. 297-306.

Berry, S., "Estimating discrete-choice models of product differentiation," The RAND Journal of Economics, 25(2), 1994, pp. 242-262.

Chowdhury, S. K., Galdo, V., and M. Torero, "Willingness to pay for the rural telephone service in Bangladesh and Peru," Information Economics and Policy, 15(3), 2003, pp. 327-361.

Comisión de Regulación de Telecomunicaciones (CRT), "Estudio de estimación de funciones de demanda de los mercados de telefonía local, telefonía larga distancia y telefonía movil y estimación de elasticidades propias y cruzadas de cada servicio," CRT Working Paper, Colombia, 2005.

Dewenter, R., and R. Haucap, "Estimating demand elasticities for mobile telecommunications in Austria," University Federal Armed Forces Economics Working Paper No. 33, 2004.

Fuss, M., Meschi, M., and L. Waverman, "The impact of mobile phones on economic growth in developing countries," In: Africa: The Impact of Mobile Phones, The Vodafone Policy Paper Series No. 3, 2005.

Grameen Technology Center, "Village phone replication manual," Grameen Foundation USA (eds.), 2005.

GSM Association, "Tax and the digital divide: How new approaches to mobile taxation can connect the unconnected," In:GSMA Mobile Tax Report, GSMA (eds.), 2005.

Ivaldi, M., and F. Verboven, "Quantifying the effects from horizontal mergers in the European competition policy," Interna- 
tional Journal of Industrial Organization, 23(9-10), 2005, pp. 669-691.

Organismo Supervisor de Inversión Privada en Telecomunicaciones (OSIPTEL), "Proyección de demanda acceso a telefonía fija en zonas urbano-marginales del Perú y conclusiones finales," Estudios en Telecomunicaciones No. 18, Peru, 2005.

Martins, M. L. C., "International differences in telecommunications demand," Information Economics and Policy, 15(3), 2003, pp. 291-303.

McFadden, D., "Econometric analysis of qualitative response models," In: Handbook of Econometrics, Vol II, Z. Griliches and M. D. Intriligator (ed.), 1984.

McKenzie, D.J., and J.P. Small, "Econometric cost structure estimates for cellular telephony in the United States," Journal of Regulatory Economics, 12(2), 1997, pp. 147-157.

Sridhar, K.S., and V. Sridhar, "Telecommunications infrastructure and economic growth: Evidence from developing countries," National Institute of Public Finance and Policy Working Paper (NIPFP), India, 2004.

Train, K., McFadden, D., and M. Ben-Akiva, "The demand for local telephone service: A fully discrete model of residential calling patterns and service choices," Rand journal of economics, 18(1), 1987, pp. 109-123.

Van der Merwe, S., "Informal institutions and development in South Africa," OECD International Seminar on Informal Institutions And Development: What Do We Know And What Can We Do?, Paris, 2006.

Wheatley, J. J., "Price elasticities for telecommunication services with reference to developing countries," World Dialogue on Regulation for Network Economies Discussion Paper (London School of Economics), 2006.

Wolak, F., "Can universal service survive in a competitive telecom- 
munications environment? Evidence from the United States consumer expenditure survey," Information Economics and Policy, 18(3), 1996, pp. 163-203. 